\title{
TEORIA I JEJ CECHY - DYSKURS W OBSZARZE NAUK SPOŁECZNYCH
}

\author{
THEORY AND ITS CHARACTERISTICS: \\ DISCOURSE IN THE FIELD OF SOCIAL SCIENCES
}

Stanisław Juszczyk*

\begin{abstract}
- ABSTRAKT
Przedstawiony tekst poświęcony jest dyskursowi na temat podstawowych pojęć w epistemologii i metodologii nauk, jakimi są: teoria, teoria naukowa, logiczna struktura teorii, a także wybrane taksonomie teorii, charakterystyka teorii pozytywistycznych (obiektywistycznych) oraz interpretacyjnych (konstruktywistycznych) w naukach społecznych. Analizę kończą wybrane przykłady teorii pedagogicznych.
\end{abstract}

Słowa kluczowe: teoria; teoria naukowa; teorie pozytywistyczne; teorie interpretacyjne
The text presented is devoted to discourse on basic concepts in epistemology and the methodology of the science: theory, scientific theory, logical structure of theory, as well as selected taxonomies of theory, characteristics of positivistic (objectivist) and interpretative (constructivist) theories in social sciences. The analysis ends with selected examples of pedagogical theories.

Keywords: theory; scientific theory; positivistic theories; interpretative theories

* Politechnika Śląska w Gliwicach, Instytut Badań nad Edukacją i Komunikacją. 


\section{Wprowadzenie}

Porównując wybrane teorie nauk ścisłych i przyrodniczych z teoriami nauk społecznych i humanistycznych, dostrzegamy istotne różnice, które dotyczą przede wszystkim: liczby tych teorii (w naukach społecznych i humanistycznych jest ich wielokrotnie więcej), ich zakresu (w naukach ścisłych i przyrodniczych, jakkolwiek ich zapis jest bardziej zwięzły, są one bardziej obszerne, obejmujące dużą rozpiętość zjawisk i mają często charakter podstawowy), struktury (teorie w naukach ścisłych i przyrodniczych mają strukturę zbliżoną do „idealnego” modelu teorii, zawierając twierdzenia - zdania logiczne, zależności między nimi, aksjomaty i hipotezy) i używanych pojęć (w naukach społecznych i humanistycznych, a w szczególności w pedagogice mamy do czynienia wielokrotnie z wykorzystywaniem pojęć podobnych, co prowadzi do ich niejednoznaczności i rozmycia teoretycznego zjawiska).

\section{TEORIA}

Pojęcie teorii pochodzi od greckiego theorein (przyglądać się, kontemplować, rozważać), ponieważ teoria jest rezultatem rozważań na temat oglądanego przedmiotu. Używał tego pojęcia w latach 1917-1931 David Hilbert w rozwijanej przez siebie metamatematyce, czyli teorii poznania matematycznego. W metamatematyce teorią $\mathbf{T}$ nazywa się domknięty dedukcyjnie taki zbiór zdań, że każda konsekwencja logiczna zbioru T należy do T. Pojęcie konsekwencji logicznej na ogół definiuje się za pomocą pojęcia reguł wnioskowania (inferencji). Zdanie $z$ nazywa się konsekwencją logiczną zbioru zdań $X$ wtedy i tylko wtedy, gdy $z$ przesłanek ze zbioru $X$ za pomocą reguł wnioskowania można wyprowadzić $z$. Teorią aksjomatyczną $\mathbf{T}$ (jest to pojęcie formalne) nazywa się zbiór konsekwencji logicznych pewnego zbioru $\mathrm{X}$ zwanych aksjomatami, w symbolicznym zapisie: $\mathbf{T}=\operatorname{Cn}(X)$ (Grobler, 2006, s. 139-142).

Jednak teorię naukową musi coś różnić od teorii matematycznej - musi ona mieć związek z doświadczeniem, czyli z interpretacją empiryczną. Teoria naukowa musi być sformułowana w pewnym języku L, będącym odpowiednim rozszerzeniem rachunku predykatów pierwszego rzędu. Język L posiada dwie niepuste klasy: terminy teoretyczne $\mathrm{L}_{\mathrm{T}}$ i obserwacyjne $\mathrm{L}_{\mathrm{O}}$. Podjęzyk $\mathrm{L}_{\mathrm{O}}$ ma pełną interpretację empiryczną, ponieważ jego terminy odnoszą się do obserwowanych rzeczy, zdarzeń czy własności rzeczy pewnej dziedziny. Aksjomaty teorii 
$\mathrm{T}$, sformułowane $\mathrm{w} \mathrm{L}_{\mathrm{T}}$ oraz tzw. reguły korespondencji $\mathrm{C}$, które są zdaniami mieszanymi, zawierają terminy zarówno obserwacyjne, jak i teoretyczne. Teorie naukowe jako systemy niemonotoniczne (w sensie teorii rozumowań) można uznać za systemy dedukcyjne w jakimś idealizacyjnym sensie. Mówiąc o teoriach w nauce, mamy na myśli twory ewoluujące w czasie, o historycznie zmiennych sformułowaniach, podlegające rewizjom i modyfikacjom (Carnap, 1956; Nagel, 1961, 1970; Hempel, 1996, 2001).

Teorie uważa się za wytwory naukowe najwyższej rangi. Systematyzacja dedukcyjna zbioru twierdzeń oznacza przekształcenie go w „teorię w sensie logicznym”, czyli zbiór „zamknięty na operację konsekwencji”. Systematyzacja aksjomatyczna polega na wskazaniu skończonego (możliwie nielicznego) zbioru twierdzeń (zwanych aksjomatami), z których można logicznie wyprowadzić wszystkie twierdzenia należące do danego zbioru. Teorię określa się też za pomocą kryterium przedmiotowego (semantycznie): przez wskazanie, o jakich "przedmiotach” jednego lub kilku typów mówią jej twierdzenia. W naukach formalnych systematyzacja dedukcyjna i systematyzacja przedmiotowa idą ze sobą w parze. Efektywne „uprawiania teorii” to stawianie właściwych problemów naukowych i konstruowanie trafnych rozwiązań (Sozański, 1995).

Przedmiotem dyskursu w niniejszej pracy będą teorie w naukach społecznych, w których nie istnieje jedna prosta definicja teorii naukowej, zaakceptowana przez badaczy społecznych. W wielu monografiach metodologicznych, dotyczących nauk społecznych bądź humanistycznych, czy też ich poszczególnych dyscyplin, różnie określamy pojęcie teorii, ponieważ brak jest jej jednoznacznej definicji. Pewne definicje teorii są stabilne, a inne elastyczne. A przecież epistemologiczne podstawy (fundamenty) teorii są jednoznaczne. Rodzajów teorii jest wiele i każdy rodzaj spełnia inne cele. David Easton (1996, ss. 1-13) dzieli teorie ze względu na: (1) zakres: makro- i mikroteorie; (2) ze względu na funkcje: teorie dotyczące zjawisk dynamicznych i statycznych, struktur i procesów; (3) ze względu na strukturę: teorie będące logicznymi systemami myśli silnie ze sobą powiązanych i teorie będące luźniej zdefiniowanymi zbiorami twierdzeń; (4) ze względu na poziom, tj. biorąc pod uwagę „systemy zachowań, których dotyczą, a które - po ich uporządkowaniu - można przedstawić na pewnej skali hierarchicznej”.

Można także dokonać analizy klasyfikacji teorii opartej na rozróżnieniu czterech poziomów (skala hierarchiczna) teorii autorstwa Talcotta Parsona i Edwarda A. Shilsa (1962, ss. 1-13), uwzględniających cztery systemy klasyfikacyjne: (1) systemy klasyfikacyjne ad hoc: zawierające arbitralne kategorie skonstruowane po to, aby uporządkować i zebrać obserwacje empiryczne. 
(2) Taksonomie pozwalające badaczom opisywać związki między kategoriami, które są skonstruowane odpowiednio do obserwacji empirycznych. (3) Struktury pojęciowe, jako kategorie deskryptywne racjonalnie wbudowane w strukturę formułowanych explicite twierdzeń, pozwalających opisywać i przewidywać obserwacje empiryczne. (4) Systemy teoretyczne łączące taksonomie i struktury pojęciowe, wiążące w sposób racjonalny opisy, wyjaśnienia i predykcje; $\mathrm{z}$ danych twierdzeń mogą być wyprowadzane kolejne.

W badaniach nomotetycznych badacz zawsze zaczyna projekt badawczy od analizy podstaw teoretycznych badanego zjawiska czy procesu (czyli formalnej lub abstrakcyjnej teorii, powstającej poprzez dedukcję - zgodnie z regułami logicznymi - hipotez, sprawdzanymi przez obserwację), natomiast w badaniach idiograficznych dąży do skonstruowania teorii (np. teorii ugruntowanych $\mathrm{w}$ danych, która powstaje w sposób indukcyjny na podstawie obserwacji świata, czyli uzyskanych danych empirycznych (Glaser, 1998; Glaser, Strauss, 2009)). Teoriami rządzi wewnętrzna logika, a także łączy je mniej lub bardziej spójna forma. Jednak istnieje istotna różnica między dziewiętnastowieczną teorią a współczesnymi pytaniami teoretycznymi.

\section{CHARAKTERYSTYKA TEORII NAUKOWEJ}

Teorie to idee na temat tego, jak działa natura. W związku z tym można spotkać określenie, że teoria naukowa to „historia idei” lub rodzaj konceptualizacji, przeciwstawianej obserwacji.

Węziej, teoria to system logiczno-dedukcyjny składający się ze zbioru powiązanych ze sobą pojęć, z których dedukcyjnie można wyprowadzić dające się sprawdzić twierdzenia. Teoria odnosi się także do praktyki, tzn. naukowcy akceptują teorię (i jej praktyczne zastosowania) jedynie wtedy, gdy jej metodologia została jasno i logicznie wyłożona. Teorie pomagają wyjaśniać i przewidywać interesujące nas zjawiska, zdarzenia i zachowania, a w konsekwencji podejmować właściwe decyzje praktyczne (Frankfort-Nachmias, Nachmias, 2001, s. 52).

W opinii Jerome S. Brunera (1978) teoria naukowa jest formą przedstawienia świata wykraczającą poza to, co możemy zobaczyć i zmierzyć. Obejmuje ona zbiór wzajemnie powiązanych definicji i związków, który organizuje pojęcia dotyczące świata empirycznego i sposób jego rozumienia.

Teoria naukowa to całość logicznie spoistych uogólnień, wywnioskowanych na podstawie ustalonych faktów naukowych i powiązanych $\mathrm{z}$ dotychczasowym 
stanem nauki. Ma na celu wyjaśnienie przyczyny lub układu przyczyn, warunków, okoliczności powstawania i określonego przebiegu danego zjawiska. Kluczowe znaczenie dla rozróżnienia, czy dana teoria jest teorią naukową, czy nie, ma obecnie kryterium falsyfikowalności; pojęcie to zostało wprowadzone przez Karla Poppera, austriackiego filozofa nauki, logika, metodologa i psychologa (Popper, 1935). W myśl tej zasady teoria, co do której nie można określić empirycznych kryteriów falsyfikacji (obalenia), nie jest teorią naukową.

W psychologii teorią nazywa się logicznie zorganizowany i powiązany zbiór twierdzeń wyjaśniających, dotyczących danego zjawiska, zdarzenia, lub układ zjawisk $\mathrm{z}$ analizowanego obszaru. Twierdzenia służą definiowaniu zdarzeń (pojęć), opisywania związków między nimi oraz wyjaśniania powodów ich występowania (Sternberg, 2001, s. 32). Z teorii wyprowadza się hipotezy, będące wstępnymi twierdzeniami na temat oczekiwanych jej konsekwencji empirycznych, takich jak wyniki badań. Główną funkcją teorii jest ukierunkowanie badań (służą temu hipotezy) i porządkowanie wiedzy empirycznej (Marx, 1963, ss. 4-46).

W socjologii istnieją trzy różne koncepcje teorii: (1) teoria ma na celu uogólnienie i klasyfikację świata społecznego. Zakres uogólnienia zmienia się od teoretyzowania na temat określonego zakresu zjawisk do bardziej abstrakcyjnych i ogólnych teorii społeczeństwa i historii jako takich; (2) tezy teoretyczne powinny być przekładalne na stwierdzenia empiryczne, dotyczące zjawisk mierzalnych lub obserwowalnych, co posłuży jako weryfikacja - jest to podejście pozytywistyczne; (3) teoria powinna wyjaśniać zjawiska, identyfikując mechanizmy przyczynowe oraz procesy, które - choć nie można ich bezpośrednio zaobserwować - ujawniają się poprzez swe efekty - takie podejście nazywamy realizmem (Marshall, 2005, s. 384; Sztompka, 1973; Kotarbiński, 1961; Ossowski, 1967).

Według Anselma Straussa i Juliet Corbin (1990, s. 15) teoria oznacza „zestaw dobrze opracowanych pojęć powiązanych ze sobq za pomoca twierdzeń dotyczących tych relacji, które wspólnie tworza zintegrowana ramę, która można wykorzystać w celu wyjaśniania lub przewidywania zjawisk”. Autorzy zaznaczają, że istnieją wyraźne różnice między teorią a opisem, w przypadku którego osoba wykorzystuje słowa w celu wywołania mentalnego obrazu przedmiotów, wydarzeń i doświadczeń. Według nich teoria ma o wiele bardziej abstrakcyjny i objaśniający charakter. Czyli teorie są abstrakcjami odzwierciedlającymi określone aspekty świata empirycznego; mówią one, jak i dlaczego zaszło dane zjawisko empiryczne.

Dobra teoria naukowa ma porządkować wiedzę zdobytą metodami empirycznymi, stanowi źródło sprawdzalnych hipotez ukierunkowujących badania 
i pozwala się weryfikować badaczom, a nawet przewiduje istnienie nieodkrytych zjawisk i ich rozwoju. Badacze oceniają teorię pod kątem jej wewnętrznej spójności, trafności jej przewidywań empirycznych oraz pojęciowej oszczędności proponowanych przez nią wyjaśnień (Shaughessy, Zechmeister, Zechmesiter, 2002, s. 45).

\section{TEORIE POZYTYWISTYCZNE (OBIEKTYWISTYCZNE) I INTERPRETACYJNE (KONSTRUKTYWISTYCZNE)}

Najbardziej rozpowszechnione definicje teorii wywodzą się z pozytywizmu uznającego, że teoria to stwierdzenie relacji między pojęciami abstrakcyjnymi, obejmującymi szeroki zakres obserwacji empirycznych. Pozytywiści traktują pojęcia teoretyczne jako zmienne, starają się określić relacje między pojęciami, a ich celem jest wyjaśnianie i przewidywanie tych relacji, natomiast weryfikacja relacji teoretycznych realizowana jest za pomocą falsyfikacji hipotez. Jest to zabieg charakterystyczny dla badań nomotetycznych. Teoria pozytywistyczna szuka przyczyn, faworyzuje deterministyczne wyjaśnienia oraz kładzie nacisk na ogólność i uniwersalność (Charmaz, 2009, s. 162; Markovsky, 2004, ss. 830-834, Strauss, 1995, ss. 7-18).

Alternatywna definicja teorii nastawiona jest bardziej na zrozumienie (co jest charakterystyczne dla badań idiograficznych), niż na wyjaśnienie. Zrozumienie teoretyczne traktowane jest jako abstrakcyjne i interpretacyjne, gdzie ma miejsce interpretacja przez teoretyka badanego zjawiska. W związku z czym teorie interpretacyjne podkreślają nieokreśloność, a nie poszukiwanie przyczynowości, odrzucają linearność rozumowania na rzecz pokazywania schematów i związków, mających raczej charakter nieliniowy. Warto w tym miejscu przytoczyć dyskusję, jaką przeprowadzili Georg Ritzer i Douglas J. Goodman (2004) na temat kryteriów klasycznej teorii socjologicznej, dotyczącej fundamentalnych kwestii życia społecznego, a zakładającej abstrakcyjne, ogólne pojęcia. Teoria ta posiada mocne akcenty interpretacyjne, tkwiące w zwróceniu nacisku na rozumienie i zakres. Należy podkreślić, że teoria interpretacyjna wymaga twórczego zrozumienia badanego zjawiska. Ten rodzaj teorii zakłada istnienie emergentnej, złożonej rzeczywistości, nieokreśloności. Przyjmuje też, że fakty i wartości są ze sobą nierozerwalnie połączone, prawda ma charakter tymczasowy oraz że życie społeczne ma charakter procesualny. Można powiedzieć, że teoria interpretacyjna zgodna jest $\mathrm{z}$ interakcjonizmem symbolicznym George’a Herberta 
Meada, czołowego amerykańskiego pragmatysty, filozofa, związanego ze szkołą chicagowską, jednego z twórców tradycji socjologicznej, która po jego śmierci jest znana jako interakcjonizm symboliczny (Mead, 1964). Jego myśl jest często określana mianem behawioryzmu społecznego.

W opinii Kathy Charmaz (2009, s. 164) celem teorii interpretacyjnej jest: „(1) konceptualizacja badanego zjawiska w celu ujęcia go w abstrakcyjnych terminach; (2) wyrażenie teoretycznych twierdzeń dotyczących zakresu, głębi, mocy oraz istotności; (3) potwierdzenie subiektywnego charakteru procesu teoretyzowania i tym samym roli negocjacji, dialogu i zrozumienia; (4) zaproponowanie twórczej interpretacji”.

Pertti Alasuutari (1996, ss. 371-384), badacz kultury, etnograf, twierdzi, że teorie są źródłem ram interpretacyjnych, dzięki którym można postrzegać rzeczywistość. Jakkolwiek laicy i badacze (teoretycy) stosują różne ramy interpretacyjne, można uważać, że zarówno jedne, jak i drugie pozwalają zrozumieć idee oraz działania laików - teoretycy badają zasady interpretacji rozumienia świata, którymi kierują się laicy, wychodząc tym samym poza sferę koncepcji stworzonych przez tych ludzi.

Teorie interpretacyjne (konstruktywistyczne) są często przeciwstawiane teoriom pozytywistycznym (obiektywistycznym), a jednocześnie okazuje się, że teoria ugruntowana ma zarówno pozytywistyczne, jak i interpretacyjne inklinacje, co przedstawiał w swoich kolejnych pracach Barney G. Glaser (1978, 1992, 1998, 2002). Zarówno teorie pozytywistyczne, jak i interpretacyjne mają charakter retoryczny. Zdaniem Barry'ego Markovsky'ego (2004, ss. 830-834) teoretyk stara się przekonać czytelnika, że pewne wnioski wypływają z przesłanek. Dlatego w teoriach przedstawiane są argumenty na temat rzeczywistości i panujących w niej relacji, mimo iż są one „oczyszczone” z kontekstu i zredukowane do pozornie neutralnych twierdzeń, przez co zbliżają się do pozytywistycznych pojęć obiektywności. W podejściu konstruktywistycznym pierwszeństwo ma zjawisko badania oraz uznaje się, że dane i analiza są tworzone na podstawie wspólnych doświadczeń i relacji z uczestnikami badań oraz innych źródeł danych. Dane i przeprowadzone analizy to społeczne konstrukcje, które odzwierciedlają proces, w wyniku którego doszło do ich powstania. Badana rzeczywistość jest dynamiczna, zmienia się, ponadto istnieją rzeczywistości (światy) lokalne oraz ma miejsce wpływ ludzi na świat lokalny i świat większy, niekoniecznie globalny. Badacz demonstruje złożoność światów, poglądów badanych i ich działań (Bryant, 2002 2003; Charmaz, 2000, ss. 509-535; Sally $\mathrm{i}$ in., 2004, ss. 1342-1365). 
Teoria obiektywistyczna zajmuje się „realnymi” danymi, a nie procesami, w wyniku których doszło do ich powstania. W związku z tym eliminowany jest kontekst społeczny, z którego wyłaniają się dane, a także wpływ badacza oraz często interakcje między badaczami, którzy stosują podejście konstruktywistyczne. Zwolennicy teorii obiektywistycznej zakładają, że dane reprezentują obiektywne fakty dotyczące poznawalnej rzeczywistości. Dane już istnieją w tej rzeczywistości, a badacz je po prostu odkrywa, wydobywa. Badacz tworzy pozytywistyczne pojęcia dotyczące analizy zmiennych czy poszukuje jednego podstawowego procesu lub centralnej kategorii w badanym zjawisku. Za istotne uznaje się badanie wielu przypadków, ponieważ w ten sposób można zrozumieć rzeczywistość oraz zauważyć różnice w stworzonych przez siebie kategoriach (Glasser, 1978; Corbin, Staruss, 1990, ss. 3-21; Glaser, Strauss, 2009).

\section{ODNIESIENIA DO TEORII PEDAGOGICZNYCH}

W porównaniu do psychologii i socjologii teorie funkcjonujące w polskiej pedagogice stwarzają wiele problemów natury epistemologicznej i ontologicznej, a także językowej. Wpływają na nie niepełne struktury teorii, zróżnicowany język opisu, różne znaczenia pojęć używanych przez tworzących je autorów, a także ich zróżnicowane podejście do opisywanego zjawiska. Typowym przykładem może być teoria wychowania, która zawiera szereg szczegółowych teorii wychowania o różnym zasięgu i poziomie, dotyczących różnych aspektów wychowania. Jest egzemplifikacją wielowymiarowości zjawiska, jego złożoności, czyli wieloaspektowości, historycznej zmienności i wielofunkcyjności. Teoria wychowania to także nazwa subdyscypliny pedagogiki, co powoduje, że badacze przyjmują różne znaczenia pojęcia ,teoria” w aspekcie epistemologicznym, jak i różne znaczenie pojęcia „wychowanie” w sensie ontologicznym (de Tchorzewski, 1993, 2002). Teoria wychowania wykazuje powinowactwo z psychologią społeczną, filozofią i socjologią wychowania, a pod względem treści głównie z etyką, estetyką oraz biologią. Tak liczne powiązania transdyscyplinowe mogą stać się wytłumaczeniem źródła niejednoznaczności w wielu teoriach pedagogicznych.

Wydaje się, że w dydaktyce ogólnej można znaleźć bardziej spójne teorie dotyczące procesu kształcenia, jakkolwiek pojęcie kształcenia należy do najmniej jasnych pojęć pedagogicznych, a to ze względu na prezentowanie odmiennych poglądów przez autorów. Taką spójność wykazuje teoria kształcenia wielostronnego, które ma rozwijać zdolności poznawcze uczących się, motywację i życie 
uczuciowe oraz zdolności do twórczej działalności praktycznej, wpływając na rozwój harmonijnie ukształtowanej osobowości uczących się (Okoń, 1987). Teoria ta posiada prawidłową strukturę, spójną siatkę pojęć, system logicznie niesprzecznych twierdzeń, służący tłumaczeniu faktów i ich przewidywaniu.

Teoriami współczesnymi z zakresu dydaktyki ogólnej, których struktura zbliżona jest do spójnej teorii, jest konektywistyczna teoria uczenia się (Siemens, 2005, 3-10; Kop, Hill, 2008) i teoria społecznego uczenia się (Brown, Adler, 2008).

\section{KONKLUZJE}

Mówiąc o teoriach w nauce, mamy na myśli twory ewoluujące w czasie, o historycznie zmiennych sformułowaniach, stale podlegające rewizjom i modyfikacjom. Pewne teorie są stabilne, a inne elastyczne. Istnieje wiele taksonomii pojęcia teoria, co powoduje, że współcześnie teoria należy do pojęć nieustannie modyfikowanych. Okazuje się także, że pojęcie teoria inaczej jest traktowane w naukach ścisłych i przyrodniczych, a inaczej w naukach humanistycznych i społecznych. Wydaje się nawet, że pewni autorzy z nauk społecznych czy humanistycznych często w sposób nieuprawniony nazywają pewne teoretyczne twory teoriami naukowymi, jakkolwiek nie spełniają one podstawowych wymogów epistemologicznych i ontologicznych. W dyscyplinach współpracujących z pedagogiką, czyli psychologią i socjologią, znajdujemy teorie bardziej wąskie, które dotyczą określonych zachowań człowieka, ale jednocześnie są one w miarę precyzyjnie skonstruowane. W pedagogice funkcjonuje (zbyt?) wiele teorii cząstkowych, dotyczących różnych obszarów aktywności człowieka i jego zachowań, w których autorzy korzystają często $\mathrm{z}$ niespójnego aparatu pojęciowego, co prowadzi do niejednoznaczności interpretacyjnej, a stąd niejasnego opisu eksplorowanej rzeczywistości. Oczywiście, teorie w naukach społecznych nigdy nie zbliżą się do niemal idealnej struktury teorii opisującej zjawiska fizyczne, chemiczne, geologiczne czy geograficzne - zbliżone do ideału są jedynie teorie matematyczne. Istotną różnicą w konstruowaniu teorii w naukach społecznych jest to, że ich przedmiotem są zjawiska, w których umiejscowiony jest człowiek, jednostka niepowtarzalna ze swymi zachowaniami, postawami i światem wartości, funkcjonujący w małych i większych grupach społecznych. Ponadto w badaniach idiograficznych badacz wchodzi w interakcje $\mathrm{z}$ badanymi w zróżnicowanym społecznie i kulturowo terenie badań. To oznacza, że teorie w naukach społecznych w dalszym ciągu będą mieć charakter szczegółowy i elastyczny, a ich liczba będzie rosnąć. 
Bibliografia:

Alasuutari, P. (1996). Theorizing and qualitative research: A cultural studies perspective. Qualitative Inquiry, 2, 371-384.

Brown, J.S., Adler, R.P. (2008). Minds of fire. Open education, the long tail and Learning 2.0. EDUCAUSE, January/February.

Bruner, J.S. (1978). Poza dostarczone informacje. Warszawa: PWN.

Bryant, A. (2002). Re-grounding grounded theory. Journal of Information Technology Theory and Application, 4(1).

Bryant, A. (2003). A constructivist response to Glaser. FQS: Forum for Qualitative Social Research 4(1). Pobrane z: www.qualitative-research.net/fqs/.

Carnap, R. (1956). The Methodological Character of Scientific Concepts. W: H. Feigl, M.Scriven (red.). The Foundation of Science and Concepts of Psychology and Psychoanalysis. Minneapolis (Minnesota Studies in Philosophy of Science, t.1).

Charmaz, K. (2000). Constructivist and objectivist grounded theory. W: N.K. Denzin, Y.S. Lincoln (red.). Handbook of Qualitative Research (ss. 509-535). Thousand Oaks, CA: Sage.

Charmaz, K. (2009). Teoria ugruntowana. Praktyczny przewodnik po analizie jakościowej. Warszawa: WN PWN.

Corbin, J., Strauss, A.L. (1990). Grounded theory research: Procedures, canons, and evaluative criteria. Qualitative Sociology, 13(1), 3-21.

Easton, D. (1996). Alternative strategies in theoretical research. W: D. Easton (red.). Varieties of Political Theories (ss. 1-13). Englewood Cliffs, N.J.: Prentice-Hall.

Frankfort-Nachmias, Ch., Nachmias, D. (2001). Metody badawcze w naukach społecznych. Tłum. E. Hornowska. Poznań: Zysk i S-ka Wydawnictwo.

Glazer, B.G. (1978). Theoretical sensitivity. Mill Valley. CA: The Sociology Press.

Glazer, B.G. (1992). Basics of grounded theory analysis. Mill Valley, CA: The Sociology Press.

Glazer, B.G. (1998). Doing grounded theory: Issues and discussions. Mill Valley, CA: The Sociology Press.

Glazer, B.G. (2002). The grounded theory perspective: Conceptualization contrasted with description. Mill Valley, CA: The Sociology Press.

Glaser, B.G., Strauss, A.L. (2009). Odkrywanie teorii ugruntowanej. Strategie badania jakościowego. Tłum. M. Gorzko. Kraków: Nomos.

Grobler, A. (2006). Metodologia nauk. Kraków: Wydawnictwo Aureus - Wydawnictwo Znak 2006.

Hempel, C.G. (1996). Philosophy of Natural Science. Englewood Cliffs: Prentice-Hall.

Hempel, C.G. (2001). Filozofia nauk przyrodniczych. Tłum. B. Stanosz. Warszawa: Fundacja Aletheia.

Kop, R., Hill, A. (2008). Connectivism: Learning theory of the future or vestige of the past? International Review of Research in Open and Distance Learning, 9(3).

Kotarbiński, T. (1961). Elementy teorii poznania, logiki formalnej i metodologii nauk. Wrocław-Warszawa-Kraków: Ossolineum. 
Markovsky, B. (2004). Theory construction. W: G. Ritzer (red.). Encyclopedia of social theory, t. 2 (ss. 830-834). Thousand Oaks, CA: Sage.

Marx, M.H. (1963). The general nature of theory construction. W: M.H. Marx (red.). Theories in contemporary psychology (ss. 4-46). New York: Macmillan 1963.

Mead, G.H. (1964). On Social Psychology - Selected papers (Heritage of Sociological Series). Edited and Introduction by A. Strauss. Chicago: University of Chicago Press.

Nagel, E. (1961). The Structure of Science. New York: Brace \& World.

Nagel, E. (1970). Struktura nauki. Tłum. J. Giedymin, B. Rassalski, H. Eilstein. Warszawa: PWN.

Okoń, W. (1987). Wprowadzenie do dydaktyki ogólnej. Warszawa: PWN 1987.

Ossowski, S. (1967). Dzieła. O nauce. T. IV. Warszawa: PWN.

Parsons, T., Shills, E.A. (1962). Toward a General Theory of Action. New York: Harper \& Row.

Popper, K.R. (1935). Logik der Forschung. Wien: Springer-Verlag Wien GmbH.

Ritzer, G., Goodman, D.J. (2004). Classical sociological theory. Boston: McGraw Hill.

Shaughessy, J.J., Zechmeister, E.B., Zechmesiter, J.S. (2002). Metody badawcze w psychologii. Gdańsk: GWP.

Siemens, G. (2005). Connectivism: A learning theory for a digital age. International Journal of Instructional Technology and Distance Learning, 2(1), 3-10.

Gordon, M. (red.). (2005). Słownik socjologii i nauk społecznych. Red. nauk. polskiego wydania: M. Tabin. Warszawa: WN PWN.

Sozański, T. (1995). Co to jest nauka. W: J. Goćkowski, S. Marmuszewski (red.). Nauka. Tożsamość. Tradycja. Kraków: Universitas.

Sternberg, R.J. (2001). Psychologia poznawcza. Warszawa: WSiP.

Strauss, A.L. (1995). Notes of the nature and development of general theories. Qualitative Inquiry 1995, 1, 7-18.

Strauss, A.L., Corbin, J. (1990). Basic of qualitative research: Grounded theory procedures and techniques. Newbury Park, CA: Sage.

Sztompka, P. (1973). Teoria i wyjaśnianie. Z metodologicznych problemów socjologii. Warszawa: PWN.

Thorne, S., Jensen, L., Kearney, M.H., Noblit, G., Sandelowski, M. (2004). Qualitative metasynthesis: Reflections on methodological orientation and ideological agenda. Qualitative Health Research. 14, 1342-1365. DOI: 10.1177/1049732304269888.

de Tchorzewski, A.M. (red.). (1993). Wychowanie w kontekście teoretycznym. Bydgoszcz: Wydawnictwo WSP.

de Tchorzewski, A.M. (red.). (2002). Z problematyki metodologicznej teorii wychowania (2002). Bydgoszcz: Wydawnictwo Akademii Bydgoskiej. 